\title{
Bases para un estudio de la sintaxis histórica del español de Chile*
}

\author{
Foundations for a historical syntax of the Spanish language of Chile
}

\author{
Manuel Contreras Seitz \\ Universidad Austral de Chile, Instituto de Lingüística y Literatura, Valdivia, Chile, \\ e-mail: manuelcontreras@uach.cl
}

La sintaxis histórica de la lengua española es un tema de estudio que ha estado postergado en los estudios lingüísticos, sobre todo si vemos los avances que otros ámbitos de la investigación han tenido. El artículo que se presenta quiere cumplir una doble finalidad: por una parte, efectuar un breve estado del arte respecto de este tema, revisando los hitos que marcan la investigación sintáctica diacrónica y, por otro lado, asentar los fundamentos para la formulación de una estudio histórico de la sintaxis del español de Chile.

Palabras clave: sintaxis histórica, español de Chile, lingüística histórica.

The historical syntax of the Spanish language is a subject of study that has been delayed in the linguistic studies, especially if we see the progress shown by other research areas. This article intends to achieve a twofold purpose: first, it wants to present a brief state of the art on this issue, reviewing the works that define the diachronic syntactic research and, second, to establish the foundations of a historical syntactic study of the Spanish language of Chile.

Key words: historical syntax, Spanish language of Chile, historical linguistics.

\section{INTRODUCCIÓN}

La cuarta [consideración] los griegos llamaron Syntaxis, los latinos costrución; nos otros podemos la llamar orden. A ésta pertenece ordenar entre sí las palabras $\tau$ partes de la oración. (Nebrija, Gramática de la lengua castellana)

En primer término, cabe señalar que los estudios de lingüística histórica han dedicado, en mayor o menor medida, buena parte de sus esfuerzos en delimitar las dimensiones sintácticas en el cambio de una lengua o de lenguas relacionadas.

\footnotetext{
* Este artículo se deriva del proyecto Fondecyt N 1085189 (Conicyt), “Crónica de Jerónimo de Vivar. Edición crítica y relectura".
} 
Según Faarlund (1990) existe una distinción aplicada usualmente a la sintaxis histórica, la que, entendida en sentido amplio, incluye las siguientes áreas:

(a) Estudios sintácticos de las primeras etapas de una lengua o de lenguas extinguidas.

(b) Descripciones de cambios sintácticos de un estado a otro a través de la historia de una lengua o de un grupo de lenguas relacionadas.

(c) Explicaciones de dichos cambios.

(d) Reconstrucción de la sintaxis de los estados preliterarios de una lengua y de protolenguas.

Para el autor, sólo las tres últimas se relacionarían directamente con la sintaxis diacrónica, mientras que la primera corresponde a un corte sincrónico de los aspectos sintácticos, nada más aplicados a una lengua en el pasado, pero correspondiente a la tradicional definición de la sincronía saussuriana. Esto no quiere decir que el primer tipo de estudios no sea necesario, todo lo contrario, está en la base de los siguientes, así como también el actual desarrollo de teorías e hipótesis referidas a la estructura sintáctica que permitirían explicar la naturaleza de estos cambios. A lo cual agrega el autor (1990: 6):

We are therefore not interested in comparing linguistic utterances at different stages. Such a comparison does not become more relevant or interesting even if we compare two random sets from the two periods in question. /.../ A real basis for historical comparison is obtained only when we compare the underlying grammatical systems of each stage. The changes that are the subject-matter of diachronic syntax are changes in the grammar of a language.

Asimismo, al entender la gramática como un conjunto de reglas que generan un conjunto infinito de oraciones -cualquiera sea la perspectiva teórica que se empleecualquier descripción que se intente hacer del sistema resultará en una aproximación, más o menos fiel, al sistema que subyace a las oraciones producidas por los usuarios de una lengua en particular. Además, y a diferencia de las estructuras fonéticas y semánticas, las sintácticas no son de observación directa, sino que más bien corresponden a la construcción de patrones abstractos formalizados por medio de una teoría lingüística, lo que hace que los usuarios tengan menos conciencia de ellas. Se ha discutido ampliamente, inclusive, respecto de las características de los patrones de cambio respecto de la sintaxis frente a la fonología, por ejemplo, ya que frente a las categorías abstractas de la primera, la segunda estaría marcada por elementos concretos que pueden ser seguidos a través del desarrollo de la lengua (el etymon ${ }^{1}$ ); sin embargo, las diversas investigaciones han demostrado que, en algunas lenguas, el uso del caso está determinado por la condición del verbo como unidad léxica más que de la oración.

${ }^{1}$ Con este concepto nos referimos al ítem léxico como constante histórica, el cual conforma un contexto que hace posible identificar un fonema en un estado con un fonema diferente en otro estado. 
El aspecto morfosintáctico es, quizás, en las consideraciones sobre la historia de la lengua, uno de los menos estudiados. Conforme este nivel lingüístico es uno de los más estables dentro de la lengua, los niveles fonéticos y léxico-semánticos son los que han recibido especial atención en los estudios lingüísticos históricos. Refiriéndose, precisamente, al cambio sintáctico, Hook (1991: 312) señala que:

What further complicates matters is that syntactic change has not been as well researched as other types of linguistic change. In part this is the result of theoretical or practical preference: Traditional linguistics, and as a consequence traditional historical linguistics, placed greater emphasis on phonology and morphology than on syntax. In fact, it has been claimed that before the advent of contemporary generative linguistics, hardly any work had been done in (historical) syntax.

Con todo, creemos que un texto como la Crónica de Vivar, uno de los primeros testimonios extensos respecto de la realidad de la época, es un documento que mostraría coherentemente algunos aspectos de orden sintáctico que serían de interés relevar. Dice Frago y Franco (2001: 15) que:

... se mantienen durante el Siglo de Oro otras variantes medievales, así la sintagmática la mi casa o mi casa, en la morfofonética verbal tenía y teníe (o tenié), tendría y tendríe (o tendrié) y vi, vio junto a vide, vido, o el empleo de ser como auxiliar de verbos de movimiento y de haber para los demás. También seguía el uso de la preposición en con el valor direccional de a (ir en casa), entre los adverbios estonces y onde junto a entonces y donde, sin que la negación del tipo no, nadie, ninguno + verbo hubiese desplazado por completo a la que reunía dos elementos negativos ante el núcleo verbal (nadie no $+\mathrm{V}$ ), como los cidianos «mas ninguno non osava», «que nadi nol diessen posada».

De hecho, no sería sino del mayor interés para un estudio sintáctico del español de Chile el verificar, de partida, si las afirmaciones que hace Alvarez Nazario (1991: 101) para el estado de la morfosintaxis del español puertorriqueño de los siglos XVI y XVII son de vigencia para nuestra región. El autor expone que:

Si en algo hubo de diferenciarse el manejo de formas y funciones de la lengua común en el todavía incipiente mundo hispánico de Indias por relación con el habla que se realizaba a la par en el territorio peninsular -y particularmente en el dominio del castellano central-, sería por la más larga vigencia, general o parcial, aquende el océano, de ciertos rasgos definitivamente encaminados al olvido en la Península, ya abandonados del todo o en abierta decadencia en el uso que ganaba mayor aceptación en los niveles superiores de cultura, y relegados a los medios menos cultos de la sociedad urbana o a los ambientes regionales de expresión dialectal.

Por otra parte, Hook (1991: 309) nos recuerda que

Syntax, as currently defined, covers a broad range of phenomena. A number of these have received relatively thorough treatment in traditional linguistics. These include the syntactic use of morphological forms, the order of syntactic elements in clause, and the combination of clauses into larger structures (i.e. into sentences). Other, more 'abstract' aspects of syntax, however, have not been dealt with as well, such as the relationship 
between corresponding active and passive expressions or between fully clausal structures and 'reduced', nominal or participial structures.

En el caso específico de la sintaxis histórica del español, Cano (1995) señala la existencia de 'zonas privilegiadas' y 'zonas discriminadas' en este ámbito de la investigación lingüística. Especial atención reciben el desarrollo de complemento directo preposicional, el orden y la redundancia en el uso de los pronombres afijos -especialmente los clíticos- o los estudios sobre la estructura de contenido de las categorías morfemáticas verbales - particularmente el subjuntivo, respeto de la forma de 'futuro' en $-\mathrm{ra}-$; mientras tanto, otras funciones oracionales se ven completamente desplazadas, como es el caso de los indefinidos, las preposiciones o el adverbio. En las relaciones interoracionales predominan las condicionales, aun cuando otras estructuras también van emergiendo en los campos de estudios tradicionales, como es el caso de las comparativas, la interrogación indirecta o la relación de valor temporal.

Con todo, existe otra preocupación central en esta materia y es que la mayoría de los estudios realizados en sintaxis histórica española tiene un carácter descriptivo -claro, probablemente moldeado por la falta de referencias previas-donde los datos a veces parecen más bien justificar una propuesta de esquema evolutivo y para manifestar el proceso que se reproduce en el estudio que extenderse como un hecho lingüístico con entidad propia. Esta casuística lleva, con frecuencia, a la inclusión de recuentos y estadísticas a partir del corpus, que se maneja como una 'representación' de un estado más que como un texto autosuficiente. Otra consecuencia de ello es la carencia de una estructura conceptual que agrupe a los trabajos realizados en este campo, donde no sean sólo los datos sino también el fenómeno mismo el que sea considerado a la hora de validar una propuesta específica. Aunque podemos encontrar trabajos relativos a la sintaxis española, cuya expresión reciente de mayor envergadura parece ser la de Company (2006), siguen faltando tratados teóricos de base hispana sobre el cambio sintáctico. Es más, Cano (1995:328) señala algo que, desde mi punto de vista, sigue siendo válido y extrapolable hoy día: "La mayoría de los estudios interoracionales en la historia del español tienen a las conjunciones como su principal materia de estudio: se trata, pues, más de estudios «léxicos» que propiamente «sintácticos»”. Con todo, el orden de palabras adquiere cada vez más una importancia mayor en los estudios de sintaxis histórica, en el entendido de que interesa explicar cómo determinadas secuencias configuran un determinado 'tipo' sintáctico, dado que su existencia supone la presencia de otras clases de ordenación. Sin embargo, no sólo se requiere de un corpus lo suficientemente amplio para validar las propuestas, sino también efectuar una discriminación clara entre los factores que intervienen en el orden del discurso respecto de lo que pertenece a las funciones oracionales (Sujeto, Objeto, etc.), a las semánticas (Agente, etc.) o a las pragmático-discursivas (Tema, Rema, etc.), distinguiendo los tipos de oraciones en que esto ocurre (principales/no principales, declarativas/no declarativas, etc.) y la naturaleza semántica de lo referido por ellas. A pesar de esto, no está de más observar si las relaciones y aparatos conceptuales propuestos por las diversas escuelas lingüísticas tienen un efecto productivo en cuanto a expresar una mejor explicación del desarrollo sintáctico de la lengua española más que con los tradicionales -como Sujeto y Objeto- o si entregan más luces respecto de definiciones y delimitaciones de las funciones, por ejemplo. 
El caso es que, como bien señala Cano (1995), parece ser que pocas nociones de la sintaxis contemporánea pueden tener mayores alcances que los conceptos tradicionales, aunque de mención especial es la noción de tema la que aporta el aunamiento de distintas etiquetas aplicadas a hechos lingüísticos diversos, sobre todo en lo que dice relación con la "topicalización". Finalmente, el planteamiento de que la sintaxis histórica deba trabajar, además, sobre la base de una 'sintaxis textual', en el entendido de analizar la manera en que se articula la sintaxis del texto, de cuáles son los principios que gobiernan la elección de procedimientos específicos en la construcción de dicho texto, como parte del proceso de interacción entre los participantes de la situación de discurso, es un desafío que debe abordarse en la medida en que ciertas etapas de la investigación vayan siendo consolidadas. Con todo, sigue habiendo cierto sesgo hacia la lengua literaria, lo cual, si bien coincide con nuestro análisis de la Crónica de Jerónimo de Vivar, no obsta porque se limite esta dimensión al estudio de una sola forma de expresión lingüística -la más codificada por lo cierto- sino que también hay que tomar en cuenta la documentación que revela los aspectos más cotidianos de la manifestación de la lengua, aun cuando éstos constituyan una instancia más compleja de analizar, como ya lo expresaban Saussure y Chomsky. De todas formas, incluso cuando la documentación no literaria tenga otros parámetros para constituir su discurso, no es menos cierto que también allí existen diversos esquemas que lo conforman y que la elección que efectúan los hablantes también depende de dichos patrones, para lo cual no estará de más recurrir a la retórica tradicional, clásica, no sólo para observar cómo da cuenta del desarrollo de la compositio, sino también para comprender en qué medida impulsa los cambios.

\section{ANTECEDENTES PREVIOS}

En el caso específico del español americano, los autores en su mayoría coinciden en que las variedades dialectales entre las distintas zonas -entre sí y en relación con España- no tienen la abundancia distintiva que caracteriza a otras áreas de la lengua, como el léxico o la fonología. Con todo, la culminación de una serie de procesos de reajuste del sistema lingüístico medieval es lo que distingue a la opción americana, ya que, en algunos casos, tiene condiciones convergentes con lo ocurrido en la Península, pero en otras, dadas las posibilidades que otorgaba el sistema, se decanta por soluciones que divergen de ellas. Asimismo, cabe señalar que, por la misma conformación poblacional y las características de la primera etapa de la Conquista, la mantención de alternancias medievales con formas modernas perdura mucho más en el Nuevo Mundo que en el Viejo, ya que en éste la difusión y adopción de las novedades en la lengua se hacen con mayor rapidez.

En este sentido, de especial relevancia e interés para el análisis sintáctico de la Crónica de Vivar es el hecho de tener presentes estas consideraciones a la hora de efectuar la matriz de rasgos sintácticos, así como los respectivos criterios, indicadores y casos que, posteriormente, conformarían el análisis global de los documentos. Para llegar a extraer, precisamente, los elementos que se han de considerar en este análisis, no hay que dejar de tener en cuenta diversos antecedentes relacionados con el punto que tratamos, por lo que se presentan, a continuación, algunos de los datos fundamentales en este sentido. 
Si bien es cierto disponemos en Chile de una amplia tradición historiográfica, que ha dado a la luz numerosos trabajos en que se recopila documentación colonial, no es menos cierto, también, que la falta de ediciones críticas del mismo lo ha hecho poco utilizable para fines lingüísticos, pero tampoco podemos dejar de mencionar que precisamente los estudios lingüísticos poco han ahondado en la perspectiva diacrónica de la lengua en nuestro territorio. En este sentido, aparte de las observaciones generales efectuadas por Oroz (1966) sobre la base de material literario, la mayor parte de los trabajos han sido dedicados al estudio de las cartas de Pedro de Valdivia.

Con todo, hubo un momento en que se realizó un estudio más sistemático, sobre la base de corpus transcrito paleográficamente, de una matriz de rasgos lingüísticos, en el marco del proyecto Dinámica del cambio lingüístico en la historia del español de Santiago de Chile (Siglos XVI-XVII-XVIII)2. Este trabajo quedará plasmado, principalmente, en las Notas para una historia del español en Chile y en la colaboración entregada para los textos publicados por la Real Academia Española de diversos países hispanoamericanos ${ }^{3}$. No quiere decir esto que no se hayan efectuado más estudios diacrónicos sobre el tema, sino que, habiendo trabajos individuales, la labor de un equipo con fines más globales terminó con estas realizaciones. En todo caso, para cualquier tipo de estudios posteriores es necesario considerar la matriz de rasgos allí propuesta con el fin de realizar comparaciones. En el plano morfosintáctico, los parámetros fueron los siguientes:

(i) Delimitación de uso de ciertos verbos:

(a) "haber" como transitivo en vez de "tener" (limitado durante el período colonial chileno, según los autores, sólo a frases hechas, como en a menester).

(b) "haber" en construcciones temporales en vez de "hacer" (de manifiesta vitalidad en los tres siglos coloniales, en casos tales como tantos años a, avra un año que).

(c) "tener" como auxiliar en vez de "haber" (registrado ampliamente en los siglos XVI y XVII, para decaer en el XVIII: V.M. tiene mandado por repetidas cédulas, teniendo reconocido el daño).

(ii) Futuro de subjuntivo: al igual que en el caso anterior, los autores señalan vigencia hasta el siglo XVII, tanto en peninsulares como en criollos, para comenzar a decaer en el XVIII. La vitalidad se manifiesta en todo tipo de documentación, tanto oficial como privada (ordenare, quisiere, se lo remitiere, por mencionar sólo algunos ejemplos).

\footnotetext{
${ }^{2}$ El proyecto fue liderado por Alfredo Matus, con la participación de Soledad Dargham y José Luis Samaniego como coinvestigadores, y de Ximena Lavín y Patricia Avilés como ayudantes de investigación. Se desarrolló entre 1989 y 1991 en el Instituto de Letras de la Pontificia Universidad Católica de Chile.

3 Matus, Alfredo; Soledad Dargham y José Luis Samaniego (1992). "Notas para una historia del español en Chile”, en Historia y Presente del Español en América, César Hernández (coord.), Junta de Castilla y León; pp. 543-564. En capítulo: Matus, Alfredo; Soledad Dargham, José Luis Samaniego, Sonia Pinto, Ximena Lavín y Manuel Contreras (1993). "Santiago de Chile", en Documentos para la Historia Lingüística de Hispanoamérica. Siglos XVI a XVIII, Anejo LIII del Boletín de la Real Academia Española, Comisión de Estudio Histórico del Español de América (ALFAL), M ${ }^{a}$ Beatriz Fontanella de Weinberg (comp.), Madrid; pp. 163-260.
} 
(iii) Formas no personales: la amplia utilización de estas formas caracteriza los primeros siglos coloniales, inclusive en la construcción de prep. en + gerundio, con valor temporal (en bolviendo, en oyendo, en allando la ocasión, por ejemplo).

(iv) Orden de los pronombres átonos: existe una amplia variabilidad en el siglo XVI respecto de la posición de los pronombres átonos, mientras que en el XVII la norma se va decantando hacia la del español moderno. Los primeros registros nos hablan de en las traer, en que le poder ejecutar, de la dar, hechan nos o hemos le rrespondido.

(v) Pronombres relativos: pocos casos de uso fuera de la norma se detectan en los documentos estudiados, donde encontramos para el plural: "donde rresidian las personas contra quien benian" y "olbidando a los niños a quien guarde Dios".

(vi) Peculiaridades en el género de los sustantivos: el período colonial se caracteriza todavía por la inestabilidad de algunos usos genéricos, como en los casos de mar, orden o audiencia ("el mejor audiencia"), este último caso por la preferencia del artículo masculino frente a vocal átona inicial.

(vii) Superlativos: finalmente, en este sentido se halla el uso estable de la partícula-ísimo en el siglo XVI para esta función, incrementándose durante el siglo XVII.

De éstos, Matus et al. (1992: 560) señalan que han resultado relevantes para una periodización del español de Chile, en el orden que se señala, (ii) - (iv) - (vii) - (iii) (i) [salvo "haber" en vez de "hacer"].

En el ámbito hispanoamericano, por otro lado, no es posible dejar de hacer referencia a la magna obra de Alvarez Nazario (1991) quien estudia, siguiendo las huellas de Menéndez Pidal, el desarrollo histórico del español en Puerto Rico. O como tan bien señala Rafael Lapesa en el Prólogo:

Así esta completa y extensa historia del español puertorriqueño registra y clasifica amorosamente los restos del substrato arahuaco en sus diversas capas, tanto en el léxico como en la toponimia, y los indigenismos de otras procedencias; el español implantado en la isla desde los albores del siglo XVI, con sus arcaísmos, populares unos y leguleyos otros; con sus afronegrismos, con la gran aportación canaria y catalana y mallorquina más reciente; y con su elaboración literaria, modesta en un principio, estimable desde el siglo XIX, rica y variada en el XX, el autor llega en su estudio hasta las generaciones del 60 y del 75.

De particular importancia se hace comentar esta obra, ya que entrega importantes antecedentes del español llegado a tierras americanas en la primera época, base de la posterior expansión peninsular por el territorio continental.

En el capítulo referido a la morfosintaxis de los siglos XVI y XVII en el español de Puerto Rico, Alvarez Nazario se refiere a las formas y empleos en los sintagmas nominal y verbal, para lo que dispone, en el caso del primero, el seguimiento y descripción de los siguientes elementos:

(a) sufijaciones del nombre sustantivo, las que seguirían la usanza antigua del español hasta mediados del XVII al menos. 
(b) sufijaciones de diminutivo y aumentativo, con preferencia de -illo, tanto en topónimos como en antropónimos, nombres de vegetales o derivados (Mayagüecillo, Alonsillo, guayabillo; higuillo, arbolillo). Siguiéndole en vitalidad, en la muestra analizada se encuentra -ico para la denominación personal (Antonico, Ysabelica, Alonsico, Diaguico, Juanico). El sufijo diminutivo que posteriormente se transforma en el predominante, -ito, aparece disminuido en esta etapa, tanto en la nominación personal como en adjetivación; mientras que la sufijación nominal en -ejo y -ajo ("animalejo, hatajo") responde a usos más bien esporádicos en la escritura, aunque el autor deduce cierta vitalidad en el habla, dado el uso que se hace en la toponimia de poblamiento antiguo (Arenalejos, Palmarejo, Capitanejo, entre otros). En tanto, los aumentativos no varían en relación con los utilizados en el ámbito peninsular, siendo las partículas hispanas comunes las que denotan este uso (-ón,-etón,-ote, -azo, -acho, -achón, -arrón, etc.).

(c) en cuanto al género y número, el autor señala que en los papeles coloniales de la muestra aún se presenta la vacilación masculino / femenino para los sustantivos abstractos en -or (como en la color), así como también en otros vocablos, hoy de uso arcaizante, como en la mar, la puente de Aguilar del mar océano. Asimismo, la confusión ante el género debido a acepciones diversas es usual en esta época en el español de Puerto Rico (la orden que se ha de tener; vino a este puerto vn caravela); además de una tendencia hacia la forma en $-a$, en alternancia con la que termina en - $O$ (suspensión de paga de deudas) o también por analogía a partir de sustantivos indígenas (yndia cariba). En cuanto al número, aunque el uso es el común hoy en día, también hay empleos del castellano arcaico de $-s$ plural para sustantivos cuyo singular termina en diptongo (bueis, leis, reis), así como el uso del plural casas para designar la construcción en que habita alguien, prolongando el uso medieval (frente a las casas reales del Gobernador).

(d) las formas y empleos del adjetivo muestran usos arcaizantes, como los casos de los determinantes demostrativos atal ("fize aqui este mio signo a tal en testimonio de verdad"), aqueste este, esotro, estotro, el posesivo mío sin apócope ("este mio signo"), el determinante de cantidad grande o el enfático mesmo, a con su vocalismo clásico, así como el uso de algunos numerales en -eno como seteno sétimo. Por otra parte, se presenta con plena vigencia la alternancia entre formas plenas y apocopadas, como en cualquier - cualquiera o grande - gran. En el caso de primero, aparece con forma plena ante sustantivo masculino, mientras que se apocopa ante femenino (primero Gobernador la primer nobleza). También se halla el uso de calificativos antepuestos o pospuestos de manera indistinta, como en "tiene pepitas muchas", "como una grande pera", o con dos adjetivos antes del nombre ("hasta estos inmediatos tiempos") donde en la negación se intercala el indefinido alguno, como en "no consintió a vagel alguno español". Asimismo, se encuentra el uso de más, menos equivalente a 'mayor' y 'menor' ("su más o menos adelantamiento o su más o menos ruina") y el uso del posesivo su reforzado en su sentido de pertenencia con de o del seguido del nombre del poseedor o del pronombre que lo representa, como en "ciertas preguntas su tenor del qual es este", "su nacimiento deste rrio" o "su carta de V. md.". En contraste con estos usos arcaizantes, se presenta la rápida adopción del superlativo adjetival en -ísimo ("esta ciudad es pauperísima", "del reuerendísimo señor cardenal"). 
(e) empleos del artículo. Usos comunes en este período son los de el, la ante un sustantivo modificado por dicho, dicha como demostrativo ("esperando que llegue a este puerto la dicha armada", "de la dicha villa"); ante sustantivo modificado por dicho y su ("se le pague el dicho su salario", "de quien el dicho su padre era devoto"). Alvarez observa que estos artículos alternan "desventajosamente con su omisión ante el tratamiento de Señor, $-r a$ ", ya que frente a casos como "convento del Señor Santiago" o "día del Señor San Clemente" se lee, con más abundancia "convento de Señora Santa Ana", "la de Señora Santa Catalina" o "sacose... por abogado $a$ Señor San Saturnino". En construcciones distributivas, se usa ante un, una, uno ("el un navio vendimos", ay tres ingenios de hazer açucar, el uno es de agua", "dos caños el uno más caliente que el otro"). Además, otro uso común es ante artículos numerales en plural como en "casi cuatrocientos hombres los doscientos de a caballo", "cien piezas de artilleria, las ochenta y seis de bronce, y las catorce de fierro colado".

(f) en el uso pronominal, todavía se detecta un predominio de nos y vos en el siglo XVI frente a nosotros y vosotros, que terminarán por imponerse a fines de siglo ("nos los religiosos", "vos los dichos oficiales", "nos hemos e tenemos"). El uso del neutro ello era, también, de frecuente uso, como en los casos de "por non thener que dar de comer a la gente, e por non me poder ayudar para ello desta ysla", "lo más firme ello se cae". En cuanto al empleo de los pronombres átonos, destaca el autor ya algunas formas de leísmo y laísmo, correspondientes a la innovación castellano-leonesa, como en "se junten conmigo para le hazer", "suplicando la hiciese una limosna para su fábrica". O también el uso de lo, los en el acusativo de cosa o persona ("no lo puede sufrir", "los e fecho tirar"). En cuanto a la posición respecto del verbo, se observa el uso tradicional del período, esto es, los elementos inacentuados van pospuestos cuando el verbo es el primer elemento con acentuación en el grupo fónico o precedido de las conjunciones $e$, y o mas, en otras palabras, en comienzo absoluto de frase, precedido de conjunción coordinante o después de pausa en la oración, como en "e dandoles", "Partome luego a Cuba", "e firmaronlo de sus nonbres" o "los que pasan a estas partes llevanlos a Tierra Firme". Por otro lado, aún se utilizan como pronombres demostrativos las formas aqueste, aquese, alternando eso sí con las actuales apocopadas éste y ése; asimismo, se encuentra vigente cuyo con valor de relativo posesivo, luego caído en desuso ("ni saber cuyas son de sertidumbre"). También se registra el uso del relativo cuantitativo cuanto, en expresiones como: "es de las mejores... de cuantas hay en la Isla" o "y cuanto le preguntaron decía de las cosas ausentes y ocultas". En cuanto al uso de los pronombres indefinidos se registran los casos de esotro y estotro, de plena vigencia en la época de Oro; asimismo, pronombre indefinido todo, ante numeral, sirve a la formación de frases pronominales tales como todos tres, en sintonía con entrambos a dos o ambos a dos. También, con significado equivalente, la expresión las más ("que los ay en las más de las casas"). El uso sustantival de poco conlleva un femenino como en "La infantería aun no es el tercio de lo que Su Magestad paga y essa poca la tiene pereciendo y desnuda". A diferencia de nuestra documentación chilena colonial, Alvarez no registra uso de naide o mesmo en la forma de este vocalismo que aún estaba vigente en el XVI en algunas zonas.

En cuanto al uso del sintagma verbal, el autor se aplica a desarrollar menos apartados pero de mayor relevancia, tales como: 


\section{(a) Del verbo:}

En el siglo XVI, según la documentación revisada por Alvarez Nazario (1991), alternan la conjugación medieval junto con la innovadora, que vendrá a ser la que se imponga finalmente: so, vo, esto, do soy, voy, estoy, doy ("e so testigo"); además, formas como truxo - trujo, o los pret. subj. truxeron, truxese - trugesen, que incluso llegan hasta mediados del XVII. Asimismo, se aprecia aún la diptongación de la [é] y el vocalismo antiguo en formas verbales como: retruxieron, trajieron, trujieron, dijieron; ymbiar, ymbié, complir, compla, andove, ovieran, oviesen, estove, ynbió, ynbiasen, oviese, dizir, asiguren, reseuir, etc. También se encuentra en el XVI el perf. absoluto vido, vide, vidieron; el imp. vía 'veía' y sus formas vías, vían llegan hasta el XVII. Se mantienen aún, para el primer siglo colonial, conjugaciones arcaicas para el fut. abs. e hip. como converná, convernía, devría, así como en el fut. porné. El gerundio seyendo 'siendo' todavía es posible de hallar, esporádicamente, durante el siglo XVI.

Por otro lado, diversas formas de participios fuertes tienen plena vigencia en este primer período colonial, como suspensos ("hasta aquí han estado suspensos mis servicios"), divisos, instruto 'instruido', conclusos ("muchos procesos conclusos"), pero también es posible hallar participios débiles obsolescentes como seydo 'sido' y proveído. Además, el empleo del pronombre de $2^{a}$ persona favorece el uso de formas que luego desaparecerán de esta modalidad de habla: (ind.) aveys, quesystes (subj.), libreys, pagueys, veais, informeys, ayays, tengays, así como (imp.) librad, pagad (pret. imp.) librásedes, acudiésedes y (fut. imp.) fuerdes. La palatalización del grupo /-rl-/ de inf. + pron. es abundante hasta el XVII, como en sostenello, traellos, etc.

Respecto de la sintaxis verbal, el uso de presente indicativo por el perfecto absoluto es característico: "al principio de la población desta ysla y muchos años después heran muy hordinarios estos huracanes..., agora se pasan ('se han pasado') diez o doze años que no los ay ('ha habido')". De plena vigencia, para el XVI al menos, es la expresión diz que en aquel mismo tiempo verbal: "por lo qual el diz que resçibia mucho agravio", "El Obispo de San Juan cuando llegó allá diz que halló...", o también sin que ("nos mandó provisión para dar dicho navío y negros a un Melchor de Torres cuyos diz eran"). El pret. imp. con valor de presente se utiliza en el llamado "imperfecto de modestia", a efecto de eludir el impacto de una afirmación certera en el presente, a través de la presentación de los hechos en el pasado ("no le quesystes ni aveys querido librar ni pagar... poniendo por escusa vos los dichos oficiales que la dicha cédula de desenbargo de los dichos salarios no se entendya sino oficiales y personas que tenian cargo de sus haziendas e quel no hera de aquellos por lo qual el diz que resçibia mucho agravio por tanto que nos pedia le proveyesemos sobrello de remedio con justicia mandando... le librasedes e acudiesedes con el dicho salario que hasta oy se le deve"). En cuanto al pret. simple, desde su primer uso americano, se prefiere para los hechos cumplidos acabadamente en el pasado ("partí de la Villa de Santo Domingo", "le mandé hacer un conuco", "entré en ella e andove por la bahya"). Con todo, el empleo del perf. perifrástico también tiene un valor de acción puntual ejecutada en el antepresente, como por ejemplo en "todo lo que en dicho viaxe a subçedido", o del pasado que llega hasta el presente, como en "no $e$ podido ser ynformado", "fasta aqui non $e$ podido facer mas", "le soplico tenga memoria como $e$ servido y como syrvo y como e gastado quanto $e$ tenido". En todo caso, el siglo XVI 
confirma el uso del pret. simple como tiempo de acciones puntuales pasadas, perfectas o durativas, aunque corrientemente su uso está dedicado al pasado 'histórico' ("el descubridor y conquistador de esta isla fue Juan Ponze de León", "tomó tierra de la banda del sur... donde fundó un pueblo", aun cuando también el perfecto absoluto se extienda hacia el pasado reciente, como en "Despues de auer dos años que padescia... con vna graue enfermedad de tisico... llegó tan al punto de morir que... en el cavildo desta ciudad le dimos licencia por noventa días".

Inclusive en el siglo XVII se encuentran modalidades heredadas del castellano medieval, como en el uso del pretérito absoluto de indicativo, por ejemplo, en la expresión de hechos ya pasados, en la forma simple ("las principales y que primero se descubrieron y poblaron fueron Santo Domingo, Cuba y Puerto Rico") o en los pasados más recientes ("La licencia para el convento de Monjas que se suplicó a Su Magestad... se alcanzó el año pasado de 1646”). En todo caso, coexisten usos que ya se vienen imponiendo en la Castilla del XVI, como el uso de la forma compuesta para señalar acciones recientemente acabadas ("De particular gusto me ha sido su carta").

En tanto, en el uso del futuro absoluto, expresión de hechos o situaciones venideras, si bien ya están vigentes usos comunes hoy en el español general, no es menos cierto que coexisten formas que luego serán superadas y reemplazadas. Así, la probabilidad presente se canaliza, en un número no menor de casos, a través del verbo haber en formas de impersonal de tiempo transcurrido -a diferencia del actual uso con hacer-, como en: "habrá quince días que llegaron aquî", o en "un navío que de aquí partió habrá un año". El futuro hipotético muestra algunos casos del tiempo simple, con la alteración del fonetismo arcaizante en casos tales como devría o convernía. Ahora bien, en cuanto a los usos del subjuntivo, éstos no se alejan de los valores actuales, como tampoco lo hace el pretérito perfecto; en tanto, de las formas construidas con - ra y -se del imperfecto, predominan casi con exclusividad estas últimas en la documentación puertorriqueña analizada por el autor. Como contrapartida, la forma en - $r a$ del pretérito imperfecto es casi inexistente, detectando el autor sólo tres casos - uno a fines del XVI y los restantes avanzado ya el XVI - ("si tubiera cada yngenio çien negros", "dotando la lámpara del aceite que pudiera gastar cada año" y "podrá el enemigo estrangero que la poseyera poblarla toda"). También con pocos casos detectados asoma el pretérito pluscuamperfecto de subjuntivo con forma compuesta ("si esta granjería del oro no hubiera çessado", "si se hubiese ido"). En cuanto al futuro imperfecto de subjuntivo, éste es abundantemente documentado en los textos puertorriqueños, en la expresión de cláusulas subordinadas de un hecho hipotético venidero, de aspecto imperfectivo ("lo que le paresciere", "cualquiera que cumpliere con el mandato"), mientras que en voz pasiva se halla a principios del XVII ("dar e entregar cada e quando le fueren pedidos e demandados"). No hay que olvidar, también, que es característica de la lengua de este período la preferencia de las formas en -ra por sobre las en -ría comunes en la actualidad, para las formas condicionales ("si no se proveyese presto, recibiera mucho daño la población de estas partes", "porque abiendo oro nada faltara" o "no hubiera el enemigo saltado en tierra, si no le hubiera mandado retirar").

En cuanto a las formas de imperativo, carecen éstas de la expresión plena de $2^{\mathrm{a}}$ persona (vos - vosotros) como en 'librad' o 'pagad', sino más bien mantienen una afinidad con el presente de subjuntivo. En el XVI se registran verbos con metátesis, como converná o convernía. Por la característica de los documentos analizados, 
el autor señala que es mucho más usual el mandato indirecto con atenuación de cortesía, en relaciones asimétricas: por ejemplo, al dirigirse a un subordinado, el mandato es terminante (vos mandamos que... veays e os informeys"), mientras que al solicitar una acción o determinación las expresiones se atenúan: "desde agora soplico me las haga", "Es de toda necesidad que venga Justicia mayor".

En tanto, las formas no personales del verbo también son tratadas por Alvarez Nazario. En este sentido, el infinitivo es el que mayor variedad presenta en los documentos analizados, pudiendo registrarse en su uso sustantivado, precedido de artículo, como en: "en el nonbrar procurador para enbiar ante vuestra alteza"; como verbo propiamente tal, en función de núcleo de subordinadas sustantivas ("fue forzado partirme a la ora", "el polvo que se levanta causa hazer lo dicho"); integrando el complemento de un sustantivo objetivo con de ("yo e acordado... de servir a su Magestad e yr a la ysla Florida"). Se observa, además, el uso de dos infinitivos contiguos como fórmula expresiva de cortesía hacia una autoridad superior, con el fin de que la solicitud manifestada revista un carácter de ordenanza desde dicha autoridad ("conviene...mandar determinar", "merced de mandar traer"). También el infinitivo integra una subordinada adverbial, con valor causal y nexo por ("una sierra mal asiento asi por no aber cosa llana en el como por tener el agua lejos y aber un varro que tiñe"), así como en función de núcleo verbal de cláusula principal, cuyo valor actual correspondería a la forma conjugada de indicativo ("estrujada la hoja desde arbol y echando el zumo dél dentro de la herida... no ser menester segunda cura para sanarle"). Aunque se trate de un fenómeno morfofonológico, el autor hace referencia a las formas palatalizadas que combinan el infinitivo con el pronombre enclítico. Por otro lado, las formas de gerundio aparecen en función de núcleo de la subordinada adverbial, usualmente con expresión temporal ("luego saliendo de allí... no quieren tocar en ella", "desto mueren muchos niños en naciendo", "porque faltando los indios, se dejaron de labrar las minas de oro"), de modo ("y echando el zumo dél dentro de la herida y pegándola al pie", "dende la dicha Cabeça de San juan viniendo por la costa abajo a la cibdad de Puertorrico, está otro rrio") o de causa ("por que abiendo oro nada faltará", "Pues estando tan cercana a la isla Española... casi inmediatamente se conquistó y pobló"). En tanto, los usos del participio pasado -descontando su valor usual de adjetivo y de integrante de los tiempos compuestos- se vinculan con cláusulas subordinadas expresivas, generalmente de anterioridad temporal ("lo qual fecho, ymbié al dicho caravelón...", "la qual dicha rrelación... consultada e platicada con miguel de pasamonte... mandó”, "acabado su término, fue preso por la Inquisición”); en otros casos que se presentan, el participio integra o inicia el núcleo de una frase adjetiva modificadora del complemento del verbo oracional ("se mudaron a la Península en que hoy está la Ciudad, que bañada del viento Este... es saludable y alegre", "ay veinte y tantas islas poseídas de los estrangeros").

En cuanto a los verbos auxiliares, en los documentos puertorriqueños coloniales de la primera época (siglos XVI y XVII) se observa la preferencia del verbo haber, en lugar de ser, en la formación de tiempos compuestos de verbos intransitivos y reflexivos - aun cuando se hallen todavía usos medievales con ser. La conjugación analógica de haber en $1^{a}$ pers. plural todavía parece en el primer tercio del XVI con un claro arraigo en el medievo peninsular ("Asi mesmo le abemos suplicado", "ciertas cartas habemos escrito"). El uso auxiliar también se presenta como haber de + infinitivo, como futuro absoluto ("sepamos en que cosa hemos de entender", 
"hemos de morir como leales vasallos") o hipotético ("la descripción e rrelación que se avia de hazer", "los hombres prudentes se habían de venir a casa a Puerto Rico"). Como se dijo, ser como auxiliar en vez de haber tiene escasa perduración, mientras que ser por estar es frecuente en el XVI ("en la manera que dicha es", "poner estanco en la sal es prohibido por leyes destos Reinos"); también hay casos de estar auxiliar ante participio ("se an hallado muchos naçimientos [de oro] en esta ysla.. que oy en dia esta por catear y buscar la mayor parte de la ysla y los que estaban hallados y se iban labrando se derrumbaron y cayeron"). Con verbos transitivos también es común el uso de tener, ante participio ("del assiento que thengo comenzado a façer", "segund Su Alteza lo tiene mandado", "le tenía muy bien conocido el Consejo"), con de + infinitivo con sentido de obligación, necesidad o determinación de hacer algo ("la ynstrucción de lo que tengo de hazer"). Complementan estos casos verbos como dejarse de + infinitivo precedido de negación -con sentido de realización a pesar de motivos en contra-, deber de + infinitivo -como suposición- y quedar + participio en sintagma perfectivo ("lo cual por nada del mundo dejará de hacerse mientras yo la ejerza", "en tiempo de dicho Obispo se debió de hacer, o por lo menos comenzar", "rrespeto de lo que atrás queda dicho").

Usual es, también, durante el siglo XVI, el emplear haber por hacer en expresiones impersonales de tiempo ("puede aver dos meses que vinieron a la ysla de Sant Joan çinco canoas de caribes", "ha cuatro años que esperamos residencia"). Asimismo, la (cuasi)identidad en sentido y uso de haber y tener, que proviene desde la Edad Media y llega hasta el XVII, nos entrega casos de tener con sentido de posesión durativa ("e se obligo de los tener en su poder"), empleo conjunto de ambos verbos con valores sinónimos -hoy en día exclusivos de tener- ("que de aquí adelante le ayays e tengays al dicho adelantado... por tal capitan", "la provision rreal que de su alteza he e tengo para husar e exercer"), u otros casos de haber con diversos sentidos de 'tener' ("se obligaua... de no... los dar.. syno fuere... a quien por su alteza los oviere de aver", "segund que lo han de uso e de costumbre", "e avemos por buenos los tales"). Además, la distinción entre hay-está, está-es para situación localizadora o de esencia (transitoria o permanente) produce continuos cruces: 'impersonal' ("en su ribera esta un arbol que se llama cayba", "Hase esta Isla, cincuenta leguas a barlovento de la Margarita"); 'copulativo o locativo' ("téngole lastima al obispo porque es solisimo a muchos trauajos que tiene", "onde antiguamente fue el pueblo"); "valor esencial y permanente' ("el mayor puerto que ay en todas las yndias por estar honda la entrada"). En cuanto a la voz pasiva, el autor señala que son usuales en la época, con diversas variaciones en los tiempos conjugados: 'presente' ("como por Vuestra Magesta es deseado"), 'pretérito' ("fue preso por la Inquisición"), 'futuro hipotético simple' ("la Real hazienda seria aumentada en mucha cantidad"), 'infinitivo' ("non e podido ser ynformado"); además, se documenta también las oraciones de pasiva refleja con se ("A unos se azotó, a otros se cortaron los pies", "no se pudieron leer sus cuadernos"), junto con construcciones cuasi-reflejas - a la denominación de Bello- con estar intransitivo ("Oprimio la tierra de calidad, que se estubo en diversas ocasiones para tener..."). La condición reflexiva o no de los verbos difiere, en algunos casos, del uso actual: "fue forzado partirme", "colocada con tal disposición, que se compiten lo agradable y lo fuerte". Del castellano antiguo hereda el habla del XVI numerosas construcciones: andar + con, andar + otro verbo 'estar', andar + a y otro verbo 'ir', andar + en 'pasar ciertas cosas que en su duración y progreso suponen un movimiento real o 
figurado'; apercibir 'preparar el ánimo', apercibirse + de 'proveer oportunamente de lo necesario'; entender + de y otro verbo 'tener intención de hacer una cosa'; estar + para 'estar a punto de'; $i r+$ por 'ir en busca de'; placer $+a$ 'agradar a, ser del agrado de'; predominar $+a$ (fig.) 'exceder en altura una cosa respecto de otra'; seguírseles 'resultarles en consecuencia': tornar, -se + a y otro verbo inf. 'volver a hacer lo que dicho segundo verbo expresa'.

\section{(b) Del adverbio:}

El uso de las formas adverbiales, sobre todo en lo que dice relación con el siglo XVI, conservan valores antiguos a lo menos: entre los adverbios de lugar, do 'donde' es aún abundante hasta mediados de siglo ("en la isla, do la Ciudad está", "por do se le hizo merced"); los adverbios medievales suso y yuso todavía están presentes, aunque es característica más propia del lenguaje notarial ("e después de lo suso dicho", "los testigos yuso escriptos"); mientras tanto, donde, precedido de $a$, revela usos anticuados con verbos de reposo ("y es adonde asiste ['está'] el gobernador") y la forma onde todavía está presente a fines del XVI ("la Baya de San Xerman onde antiguamente fue el pueblo asi llamado"). En cuanto a los adverbios de tiempo, agora es una forma que sigue teniendo vigencia aún en el siglo XVII, aunque también exista la alternancia con aora ("e agora va él con el remanente", "como yo lo pudiera hacer agora"); dempués 'después', forma del ant. astur-leonés, mantiene su utilización en frase prepositiva con de pospuesto ("dempués de pasada la dicha tormenta"). A inicios del XVI, se verifica también el uso de desque con valor relativo de 'cuando' ("busque otra vez alli assiento e desque no lo allé, volví al dicho rio ana"), así como cuanto como relativo temporal ("que quanto semejantes diferencias touiesen"). En relación con los adverbios de modo, se presente la alternancia así ansí durante el XVI ("debdas que asy se fizieron" "puedan ansí sus magestades"), el uso del relativo cual equivalente a 'como' ("Siendo cual conviene") y el de como con sentido de 'cuales', 'según' y 'sobre cómo' ("tiene pobladas las mayores y mejores, como son la Martinica..., Guadalupe, Las Nieves", "a los dos tercios de la isla como se viene oriente a poniente", "tengo carta suya como se hallaba con alguna mejoría"). El autor señala que, de los adverbios en -mente, eran de uso más común que el de hoy juntamente 'concurrentemente' y proporcionablemente 'proporcionalmente'.

De otro lado, respecto de los adverbios de cantidad, su utiliza cuan -apócope de cuanto- ante adjetivos y adverbios ("e cuan cumplido e bastante poder yo he y tengo", "y esta ya se ve quan poco podrá ser"), así como cuanto sin apocopar en usos distintos al moderno ("quanto desdichada y arruinada quedaría aquella isla"). El lenguaje notarial conserva aún en el XVI el otrosí con valor de 'además' (e otrosy mandamos a los conçejos"); con el mismo valor se encuentra más ("dos mugeres e vn onbre e mas un niño chico"), así como con su valor corriente antepuesto al verbo -en infinitivo y gerundio- ("non se a podido mas facer", "se va mas arruinando"). Otro apócopo registrado es тиy -de 'mucho'- ante adjetivo comparativo ("muy mejor lo podrá el desde acá proveer") o también junto al cuantitativo más ("otro rrio muy mas caudaloso", "toda la banda del norte es mas muy tormentosa"). El uso del adverbio sólo es tan raro en el XVI que el autor detecta un caso a mediados del siglo ("El Prior [entre los demás religiosos de su orden] solo es persona calificada"), aun cuando se presentan otros casos respecto de numerales, pero con concordancia 
de género y número ("hay dos solas poblaciones en la costa", "dos hijos que tenía solos", "la población es sola una"). De los adverbios de afirmación, se aprecia el uso de asimismo 'también' ("e vista asymismo una çedula firmada de sus altezas"), en este mismo sentido se utiliza item ("Item: fice facer dos pedazos de labranza"). La negación manifiesta esporádicamente aún el non medieval ("non e podido ser ynformado", "de cuya cabsa non se a podido mas facer"); y en la duda, tal vez aparece más bien con el sentido de 'a veces, alguna vez' ("no consintió a vagel alguno español de los que tal vez pasauan que le diesse...”).

Otra serie de locuciones adverbiales son comunes en la época. De carácter locativo podemos encontrar: en contorno 'alrededor', en el contorno 'en los alrededores', de dentro 'adentro' y de fuera 'afuera'. Con sentido temporal se registra: a las veces 'a veces', a la sazón 'entonces, en aquella ocasión', a las más veces 'la mayor parte de las veces', $a$ o en los principios 'al principio, en el principio', de antiguamente 'en lo antiguo', de cada año 'año tras año', de cada día 'día tras día', de poco (tiempo acá) 'hace poco tiempo', (por) espacio de un Credo 'el tiempo que dura rezar un Credo', hoy en día 'hoy día', por horas 'en cualquier momento', por veces 'repetidas veces, en alguna ocasión o tiempo'. También hay construcciones del tipo a / a los + indicación de fecha de una acción o estado, adv. ahora + especificación de tiempo transcurrido, $d e+$ especificación de tiempo pasado o futuro, iniciada con día de + indicación del nombre del santo de esa fecha, v. haber + indicación de tiempo pasado, por + indicación temporal específica ("estaba con su gente a postrero de Agosto", "habiendo entrado a los primeros de Agosto"; "ahora tres meses llegaron aquî", "para seguir mi viaje de aquí a cinco o seys dias", "salió día del Señor San Clemente a 23 de noviembre", "partió a Santo Domingo habrá cuatro días", "vino a su Obispado... por el año de 1603"). En relación con las locuciones adverbiales de modo, tenemos: a mareas 'con la marea alta', a más andar 'aprisa, rápidamente', a pie enjuto ' sin mojarse los pies al andar por sitio donde hay o debiera haber agua', a vista de ojos 'que uno ve por sí mismo; evidentemente', al / para el efecto 'con o para el propósito o fin', con [determinado] color o palio 'con determinado pretexto', de certidumbre 'con certeza', de cumplido 'cabalmente, exactamente', de llano en llano 'clara y llanamente', de su mano 'por sí mismo', (de) todo punto 'enteramente, sin que falte nada', en cristiano 'al modo de los cristianos', en gran manera 'en alto grado, mucho, muy', en propósito 'proporcionado u oportuno para un fin determinado', muy presto 'pronto y ligeramente, con brevedad y presteza', por extremo 'en extremo, con extremo'. Finalmente, en cuanto a las adverbiales de cantidad: a sumas 'en grandes sumas', cuando más 'a lo más', cuando menos 'a lo menos', harto mayor 'sobradamente más grande', cuanto un tiro de ballesta 'a la distancia de un tiro de ballesta'.

En términos generales, Alvarez Nazario (1991) recuerda que la construcción de la oración se caracteriza por ser de extrema longitud, sobre todo, aun cuando no exclusivamente, en los documentos notariales, integrada por cláusulas numerosas en relación de coordinación o subordinación, frecuentemente unidas entre sí por una conjunción copulativa $(e / y)$; recién a mediados del XVII puede apreciarse el uso habitual del párrafo constituido por varias oraciones de menor amplitud. También destaca las diversas 'irregularidades' de orden y función en la expresión escrita, más propiamente caracterizadoras de la lengua hablada, lo cual ocasiona desajustes en la cohesión gramatical del discurso: colocaciones adjetivales no adyacentes al sustantivo ("por umedad que thenia demasiada aquel asiento"), anacoluto ("y del toma el nombre 
cierta población que alli esta de españoles"), orden complemento-verbo-sujeto ("Las armas que tiene le dio Su Magestad"), pero que también podemos rastrear en los escritos medievales y de otras regiones americanas. Asimismo, la concordancia entre el verbo y el sujeto suele verse alterada, al menos en el XVI, en casos tales como: "y suplico venga artilleria y municiones", donde el elemento próximo al verbo ejerce de foco para la equivalencia gramatical. También, en construcciones atributivas con ser en singular, se halla el sujeto en plural y el predicado nominal en singular ("los yndios desta ysla era gente mansa"), mientras que el uso del relativo (que) con antecedente plural registra casos de verbo singular ("y derrueca los platanales que es una fruta que sirve de sustento"). Además, los textos presentan usos de construcciones elípticas propios de la época ("mandé tres barcos y veinte [soldados] de caballo por tierra", "se tiene por [ser] de mejores calidades"); uso de "e mas non" como expresión de cierre ("esto es lo que fasta agora se a podido facer, e mas non"), así como el uso abundante de la reiteración cercana en el discurso de dicho, $-a$ ("comence a seguir el dicho viaxe para la dicha ysla").

El otro hito que necesariamente debe tenerse en consideración, dada la magnitud de la obra y por la visión de conjunto que entrega, es el texto bajo la dirección de Concepción Company (2006), Sintaxis histórica de la lengua española. Primera parte: la frase verbal. Esto es, once años luego de que Cano (1995) hiciese referencia a las carencias que aún tenía el estudio de la sintaxis histórica hispánica. El texto, en su fundamento, permite la interacción de la filología hispánica tradicional con enfoques de desarrollo posterior en lingüística histórica. No es de menor relevancia indicar, por cierto, que la obra presenta un total de 3.321 ejemplos y unos 300 cuadros y esquemas que sintetizan los más diversos aspectos en estudio. En esta obra colectiva, el plan expositivo común de la misma queda manifestado por la autora en cuanto al abordaje de aspectos concretos como:

presentación del problema, una breve revisión bibliográfica del estado de la cuestión realizada por problemas y no por autores, análisis de los diversos aspectos, factores o variables pertinentes para dar cuenta del tema en su relación sincrónica-diacrónica, diacronía del fenómeno, que muchas veces constituye un concentrado de aspectos diacrónicos previamente tratados o esbozados, y, a manera de conclusiones, un balance general de la información expuesta en el capítulo; cierra cada capítulo el corpus base seleccionado por el autor y las referencias bibliográficas.

Cabe destacar que, como señala la obra, se trata de una sintaxis histórica del español, es decir, abarca desde el período medieval hasta el siglo XX, desde las Glosas emilianenses y silenses (c. siglos X-XI) hasta La Tempestad (1997) de Juan Manuel de Prada, pasando por textos como El libro del cavallero Zifar (s. XIV), la Historia... de Bernal Díaz del Castillo (s. XVI), La portentosa vida de la muerte (s. XVIII) de Joaquín Bolaños o los Textos para la historia del español (1991) de la Universidad de Alcalá de Henares. En total, 93 obras que se distribuyen en 39 del período medieval, 17 relativas al español 'clásico' (siglos XVI y XVII), 14 entre los siglos XVIII y XIX y 18 de ellas en relación con el siglo XX, descontando que dentro de ellas hay cinco textos que recopilan material documental de diversas épocas. Otro rasgo relevante que presenta la obra es que, tal como señalaba Cano (1995), los trabajos que se presentan se han elaborado sobre la base de tener en cuenta las construcciones sintáctica y no 
los elementos léxicos o clases de palabras que forman dichas estructuras, lo cual, tal como hacía ver nuestro citado autor, había sido la característica de los estudios de sintaxis histórica española hasta mediados del siglo XX. Asimismo, la base referencial para el análisis es un corpus extenso -que ya no de obras específicas-, por lo cual puede obtenerse una visión de conjunto y una mejor comprensión de los cambios gramaticales que va experimentando la lengua. Esto supone, como no, un desafío a la hora de realizar un estudio en una obra en concreto como la Crónica de Jerónimo de Vivar, ya que, si bien se estudia la sintaxis en un texto en particular, se tienen suficientes referencias generales como específicas para poder concretar el contexto de la situación lingüística de la obra, así como para comprender las peculiaridades idiomáticas de la misma.

El trabajo sobre la frase verbal que presenta la obra dirigida por Company se estructura en cinco partes, las cuales se presentan brevemente a continuación por dos motivos: en primer lugar, considero de suma necesidad considerar este reciente trabajo sobre sintaxis histórica del español para cualquier referencia respecto de este nivel lingüístico en la historia del español americano. Si bien contamos con obras como las de Rojas (1985) sobre el español de Tucumán o la de Fontanella (1987) sobre el bonaerense, la de Company -si bien no referida específicamente al contexto hispanoamericano- entrega las herramientas necesarias para la comprensión de la lengua española en dicho contexto, ya que se sitúa desde el ámbito medieval en adelante. Estas consideraciones no deben quedar relegadas a la hora de planificar una matriz de rasgos para seguir en la Crónica. En segundo lugar, esta obra, que tarde nos ha llegado, merece tener una difusión mayor, por lo que me permitiré extenderme en este plano, con el fin de dar a conocer sus aspectos más relevantes, no tan detallados como en el caso de Alvarez Nazario, quien trataba este tema en un apartado de su obra, al contrario de Company que dedica dos volúmenes (alrededor de 1.400 páginas) sólo a la frase verbal, pero sí lo suficiente como para dar cuenta de los puntos fundamentales de cada parte.

La primera sección se refiere a El paradigma verbal, y en palabras de la misma Company (2006: XIX-XX): "Incluye los valores de las formas pretéritas de indicativo y subjuntivo, la reestructuración diacrónica del subjuntivo, así como dos capítulos sobre la formación de los tiempos de creación romance: los tiempos compuestos y los futuros condicionales". Este apartado se encuentra formado por cuatro capítulos. El primero de ellos, escrito por José G. Moreno de Alba ("Valores verbales de los tiempos pasados de indicativo y su evolución"), se refiere al desarrollo histórico del pretérito de indicativo, con especial énfasis en la caracterización del indefinido y el pretérito anterior como tiempos nuevos en nuestra lengua románica -lo cual tiene implicancias en la gramática- así como la descripción del presente con valor histórico. En el segundo capítulo ("Las formas verbales subjuntivas. Su reorganización modo-temporal"), desarrollado por Alexandre Veiga, el autor trata de los tiempos del subjuntivo, de su valor irreal / no irreal, de los cambios que se producen en relación con los demás tiempos verbales, especialmente el verificado con el imperfecto en $-r a$, procedente de la regramaticalización del pluscuamperfecto de indicativo, y al futuro, que sufre un proceso de desgramaticalización. Por otra parte, en el capítulo 3 ("Tiempos de formación romance I. Los tiempos compuestos"), Patrizia Romani examina la creación 
y consolidación de los tiempos compuestos en español durante los siglos XII al XV a partir de las perífrasis verbales formadas por haber + participio y ser + participio, el valor transitivo o intransitivo del compuesto y la variación morfológica del participio, explicando el triunfo del primer tipo ya en el siglo XVI, cuestión de suyo importante para nuestro trabajo, como se ha podido apreciar en relación con las fuentes antes referidas. La misma Company, en el capítulo 4 ("Tiempos de formación romance II. Los futuros y condicionales") complementa el estudio anterior al investigar las causas y consecuencias de la sustitución del futuro flexivo latino por los futuros romances, así como las diferencias que presentaron principalmente durante todo el español medieval y parte del clásico los futuros analíticos frente a los futuros sintéticos, con el fin de explicar el triunfo en español de estas últimas formas.

La segunda sección, Los argumentos del verbo, consta de cuatro capítulos "que estudian los objetos directo e indirecto, cambios en el régimen verbal y en su manifestación formal, la concurrencia de ambos objetos en oraciones bitransitivas, y el problema ya clásico de leísmo, laísmo y loísmo" (Company 2006: XX). En el capítulo 5, de Brenda Laca ("El objeto directo. La marcación preposicional”), se trata de la evolución no terminada de la inserción de la preposición $a$ ante el complemento directo en español, con especial atención al proceso de adquisición de dicha marca por las diferentes categorías gramaticales (pronombres personales tónicos, nombres propios animados, definidos humanos, indefinidos humanos y definidos animados) a partir de la validez de la escala de animación/definitud, tal como lo plantea la propia autora. En el siguiente capítulo ("El objeto indirecto"), Company nos enseña la evolución del complemento indirecto en español, de su orden en la oración, tipos de verbos con los que aparece, así como de su duplicación mediante un pronombre personal átono, haciendo especial referencia a los rasgos distintivos que presenta este tipo de construcción en la modalidad dialectal mexicana. El apartado escrito por Rosa María Ortiz Ciscomani (capítulo 7, "La bitransitividad") trata sobre el análisis de las construcciones en donde se encuentran al mismo tiempo un complemento directo y un complemento indirecto -consideradas como estructuras independientes-, los rasgos gramaticales y léxico-semánticos de estos objetos, orden oracional, el tipo de verbos que puede aparecer con esta clase de construcciones, así como la presencia o no de la marca preposicional del complemento directo en función del indirecto. Finalmente, en el capítulo 8 ("Leísmo, laísmo y loísmo”), Marcela Flores Cervantes indaga acerca del origen -los antecedentes latinos del fenómeno-, así como las motivaciones que dieron lugar a esta variación en español, a fin de explicar no sólo la diferencia de frecuencia con que aparecen estos cambios, sino también la diversa aceptación y valoración social del rasgo en estudio.

La tercera parte de esta obra, Voz media y diátesis, dedica casi 120 páginas al análisis de "uno de los cambios más caracterizadores de nuestra lengua, a saber, el enorme desarrollo y polisemia de las construcciones con se". El único capítulo de esta sección, de Sergio Bogard ("El clítico se. Valores y evolución”), aborda las funciones de este reflexivo desde el siglo XII, período en que ya habría alcanzado los valores que posee en la actualidad (marcador de sentido reflexivo y recíproco, marcador de voz en el caso de la activa impersonal y la pasiva refleja, marcador aspectual perfectivo y marcador de afectación), así como la evolución de su distribución respecto del 
verbo (se - V / V - se). Por otro lado, la cuarta sección, se dedica a Algunas clases de verbos, donde se analizan los cambios en los verbos de movimiento, causativos y de posesión, así como los reajustes en la transitividad o intransitividad de dichos verbos. El capítulo 10, de Chantal Melis ("Verbos de movimiento. La formación de los futuros perifrásticos"), se ocupa de este tipo de verbos y de su gramaticalización mediante su uso metafórico apuntando, en principio, a la formación de perífrasis verbales de tipo aspectual (pasar / tornar / volver $a+$ infinitivo), su posterior evolución hacia la modalidad (llegar / venir / ir a + infinitivo) y después a la temporalidad, con el surgimiento de los futuros perifrásticos en español (principalmente, ir $a+$ infinitivo). Milagros Alfonso Vega, en "Verbos causativos" (capítulo 11), estudia estos elementos verbales para sacar a la luz sus propiedades homogéneas, tanto de tipo sintáctico (rección de una oración subordinada, diferentes sujetos que intervienen en la causación, existencia de dos predicaciones) como de tipo semántico (expresión de la causa de la ejecución), así como los cambios en su evolución durante el español medieval. Finalmente, en el capítulo 12 ("Posesión y existencia. La competencia de haber y tener y haber existencial"), Axel Hernández no sólo presenta un estudio de los factores que intervienen en la compleja evolución de los verbos haber y tener en español, en donde se produce un proceso de sustitución de haber por tener, además del origen de las construcciones existenciales con haber en donde se establece una relación con las construcciones con haber posesivo, sino que nos entrega un punto teórico que permite comprender tanto a historiadores de la lengua como a estudiantes la real dimensión del estudio de ciertos cambios lingüísticos en particular, sin tener que remitirse a esquemas hechos pero no necesariamente internalizados.

La quinta sección, finalmente, Otros cambios en la frase verbal, lejos de ser una especie de 'cajón de sastre' o de 'varios', a manera de apéndices que han quedado pendientes y no encuentran estructuración, se concentra en estudiar los problemas de orden de palabras: "el comportamiento de los complementos locativos, muchas veces fronterizos entre argumentales y adjuntos, la negación y el desarrollo de la doble negación, y los cambios en la colocación de los pronombres átonos en dependencia de la forma verbal". Tres capítulos constituyen esta parte del texto: el 13 ("La expresión de la negación"), redactado por Bruno Camus Bergareche, quien trata la negación en español medieval, con especial énfasis en la negación doble, donde aparecen los indefinidos negativos medievales en entornos negativos; así como de la evolución de la sintaxis de las palabras negativas hasta el español moderno, en donde, entre otros fenómenos, se produce la desaparición de la negación doble preverbal, y de la evolución de la negación en el dominio romance como un proceso general y común a toda el territorio. Por su parte, José María García-Miguel, en el capítulo 14 ("Los complementos locativos") no sólo se dedica al desarrollo histórico de estos complementos en el español, sino también a las categorías sintácticas (preposición + nombre común, adverbios deícticos) y semánticas (persona, objeto, lugar) que aparecen en este tipo de construcciones, además de los verbos que se construyen con éstos, y de la confluencia de varios complementos locativos en una misma oración. En último término, Dorien Nieuwenhuijsen, de la Universidad de Utrecht, se refiere, en el capítulo 15, a los "Cambios en la colocación de los pronombres átonos", analizando las propiedades de los pronombres personales átonos en español y la evolución de su 
posición en la oración, tanto con verbos en forma finita (anteposición y posposición en oraciones principales y subordinadas), como con verbos en forma no finita ${ }^{4}$.

\section{Propuesta de matriz de Rasgos}

Teniendo en consideración los aspectos precedentes, se determinó una matriz de rasgos para el seguimiento en la Crónica de Jerónimo de Vivar, atendiendo a la pertinencia que debían tener los indicadores seleccionados en virtud de representar una continuidad respecto de estudios previos en el español de Chile, como en cuanto a los aportes realizados en el ámbito específico de la sintaxis histórica del español, en el marco de teorías más generales sobre el desarrollo de la lengua y no sólo en el contexto americano. Esta matriz se encuentra agrupada en tres grandes campos, inicialmente, siguiendo la propuesta de Bosque y Demonte (1999): (a) sintaxis de las clases de palabras, (b) construcciones sintácticas y (c) flexión verbal: relaciones de tiempo, modo y aspecto. Para no tratar de complejizar excesivamente el estudio de caso que llevamos a cabo con la Crónica, se ha decidido distribuir en la matriz los rasgos que se han visto como relevantes por los autores señalados, esto es, se ha incorporado la propuesta elaborada por Matus et al. (1992) con la finalidad de establecer la necesaria comparación con los datos aportados; por lo mismo, se consideraron los aportes de Alvarez Nazario (1991), ya que da a conocer el estado de lengua de los primeros años de la Conquista peninsular, asimismo, y aunque no los hemos reseñado aquí por ser más conocidos, también han estado presentes los trabajos de Fontanella (1987) y Rojas (1985). El marco de referencia, sin duda, lo constituye la obra de Company, en lo que se refiere al sintagma verbal -aun cuando se anuncia prontamente la segunda parte dedicada al sintagma nominal, con lo cual se contaría con el marco completo actualizado. En una segunda etapa se procederá a una marcación del texto, de acuerdo a las pautas establecidas por el CORDE (Corpus Diacrónico del Español), con el fin de recuperar la mayor cantidad de información posible respecto de las relaciones textuales en éste y otros documentos ${ }^{5}$. Como dijimos, entonces, la matriz de rasgos se constituye de la siguiente manera:

\footnotetext{
${ }^{4}$ No se puede dejar de mencionar, aunque sea brevemente, el texto de Kabatek (2008) quien, al igual que Company (2006), es editor de una obra sobre sintaxis histórica del español. Sin embargo, este texto se enmarca en las tradiciones discursivas (TD) y hace referencia, por tanto, a obras y casos específicos, ya que como señala el profesor de Tübingen: "En los trabajos de este volumen que presentaremos brevemente a continuación, se discuten tanto aspectos teóricos de la cuestión de las TD dentro de las teorías del lenguaje /.../ como cuestiones metodológicas y aspectos concretos que intentan, o bien identificar TD particulares /.../, o bien relacionar las evoluciones de ciertos fenómenos lingüísticos con ciertas TD /.../" (pág. 12).

5 En el CORDE se utiliza un Prontuario de Marcación SGML, que considera las marcas -intratextuales y de estructura de corpus- para las diversas tipologías diacrónicas de los textos que pudieran encontrarse, tanto en prosa como en verso. En nuestro caso, se utiliza el editor XML/XSLT Cooktop 2.5 que cuenta con un validador para verificar la sintaxis de la codificación, lo cual permite detectar las "partidas falsas" o aquellos elementos que no cuentan con un cierre en su descripción.
} 
(a) Sintaxis de las clases de palabras

(b) Construcciones sintácticas

\section{(c) Flexión verbal}

* Sustantivos: género, sufijaciones.

* Adjetivos: superlativos, sufijaciones.

* Preposiciones

* Adverbios

* Determinantes: artículos

* Uso de los pronombres: orden de los pronombres átonos, pronombres relativos

* Leísmo, laísmo y loísmo

* Construcción del sintagma nominal.

* Transitividad e intransitividad.

* Construcciones pasivas.

* Construcciones con se.

* La subordinación.

* La predicación.

* Complementos predicativos.

* La negación.

* Construcción del sintagma verbal.

* Empleo de tiempos verbales (simples y compuestos): delimitación de uso de verbos como 'haber', 'tener' y 'hacer'; empleo del futuro de subjuntivo, etc.

* Relación tiempo verbal - sintaxis oracional.

* Complementos adverbiales temporales.

* Modalización.

* Uso de verbos auxiliares.

* Uso de formas no personales del verbo.

\section{Primeros avizoramientos}

Se ha trabajado con una versión paleográfica de la Crónica que he realizado para estos fines, en formato de texto (txt), para utilizar el programa Concordance. Dicho programa es una herramienta para el estudio de textos que permite efectuar un índice de cada una de las palabras que aparecen en el documento. Cada ejemplo se muestra con su respectivo contexto ilustrativo, acompañado de la referencia donde se halla dicho caso en el texto original. Esto permite comparar todos los usos de las palabras, lo que hace posible rastrear una amplia variedad de aspectos relacionados con el significado y la función sintáctica de los elementos. En la Figura 1 puede apreciarse un ejemplo del programa, el cual funciona -como dijimos-con archivos con extensión txt. En la columna de la izquierda ("headword") pueden verse los lemas en orden alfabético, con la indicación del número de apariciones. En ciertos casos, se observaría la variación gráfica en algunos de los vocablos, el contexto -que contempla por defecto ocho palabras antes y después del lema principal-, el cual puede ampliarse sin dificultad, así como la indicación, en la columna derecha, de la ubicación en el texto. 
ESTUDIOS FILOLOGICOS 44: 27-50, 2009

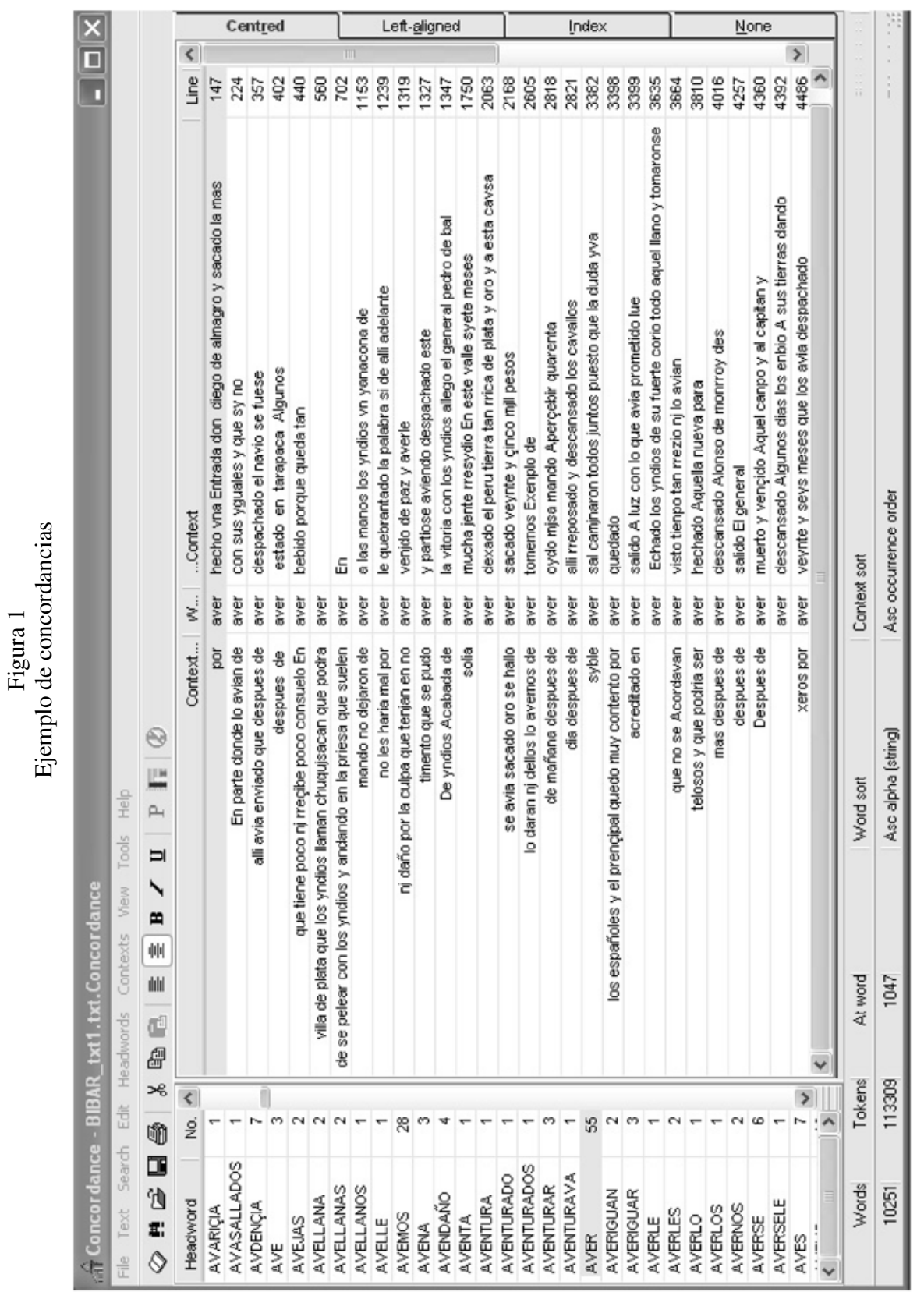


BASES PARA UN ESTUDIO DE LA SINTAXIS HISTORICA DEL ESPAÑOL DE CHILE

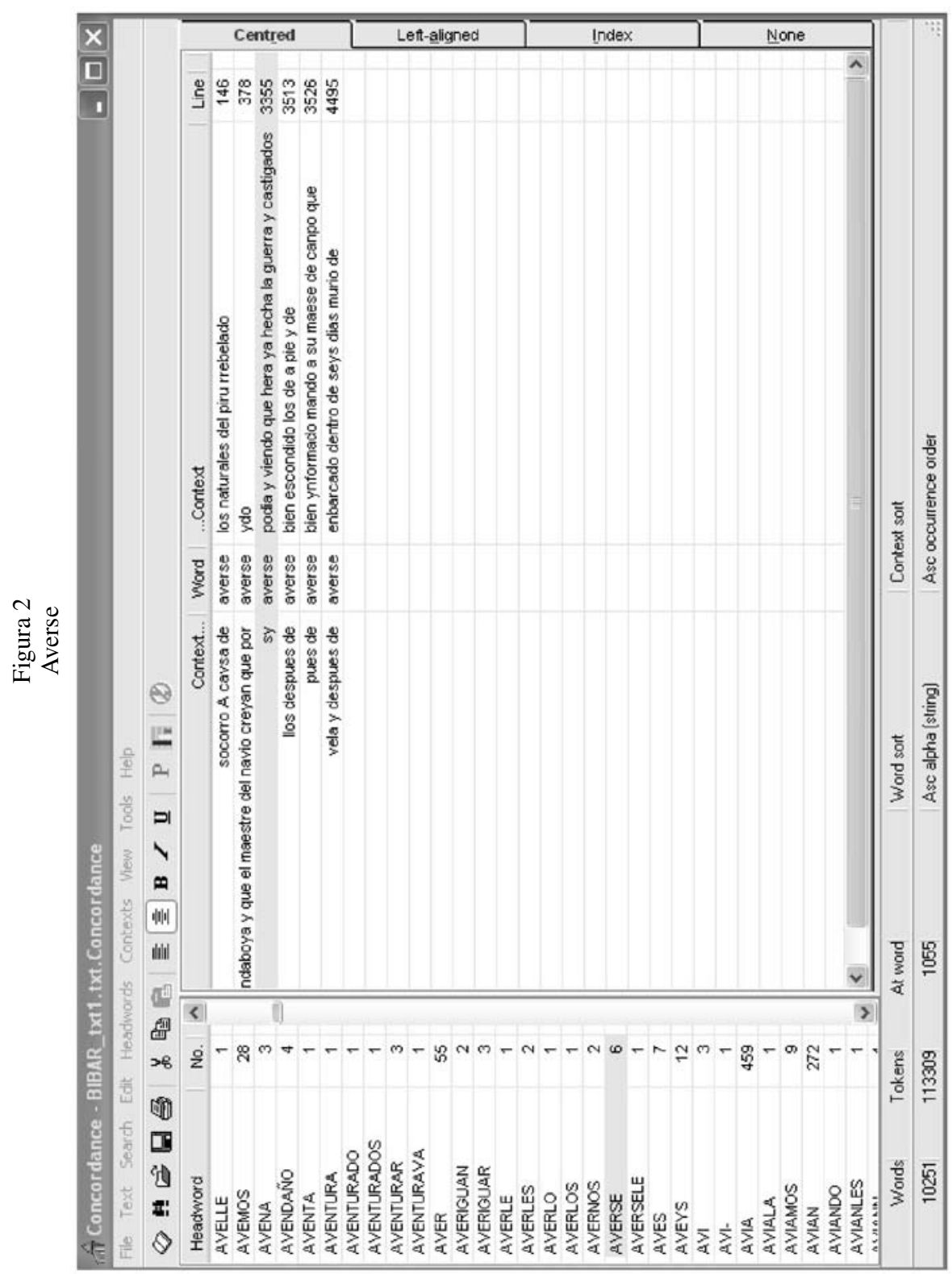


Cabe hacer notar que utilizamos una transcripción donde se han desplegado las abreviaturas, utilizando para ello los parámetros lingüísticos del propio texto o, en caso de no ser posible tal circunstancia, los del mismo autor en algún otro documento disponible. Los criterios de transcripción utilizados inciden, naturalmente, en el despliegue de las colocaciones y, según el que se escoja, puede generar algunas dificultades cuando se trata de analizar los textos de manera automática. Por ello, para la edición vinculada al corpus anotado, con miras a su posterior procesamiento computacional, se preferirá trabajar con una edición filológica crítica. En todo caso, la plantilla que sirve para iniciar el trabajo es simple y se corresponde con la información que entrega el programa Concordance. La base de datos se presenta en la Tabla 1, siguiente. Luego, la Figura 2 nos muestra el despliegue de 'averse', que figura con seis coincidencias

Tabla 1

Base de datos sintáctica

\begin{tabular}{|c|c|c|c|c|c|c|c|}
\hline Id & $\begin{array}{c}\text { Unidad } \\
\text { sintáctica }\end{array}$ & Contexto & $\begin{array}{c}\text { Docum.-Lugar- } \\
\text { Fecha }\end{array}$ & Subcampo & $\begin{array}{c}\text { Categoría } \\
\text { gram. }\end{array}$ & $\begin{array}{c}\text { Significado/ } \\
\text { Función }\end{array}$ & $\begin{array}{c}\mathrm{N}^{\circ} \\
\text { palabras }\end{array}$ \\
\hline (Autonum.) & & & & & & & \\
\hline
\end{tabular}

Tabla 2

Ejemplo de llenado y observaciones

\begin{tabular}{|c|c|l|c|c|c|c|c|}
\hline Id & $\begin{array}{c}\text { Unidad } \\
\text { sintáctica }\end{array}$ & \multicolumn{1}{|c|}{ Contexto } & $\begin{array}{c}\text { Docum.-Lugar } \\
\text { Fecha }\end{array}$ & Subcampo & $\begin{array}{c}\text { Categoría } \\
\text { gram. }\end{array}$ & $\begin{array}{c}\text { Significado / } \\
\text { Función }\end{array}$ & $\begin{array}{c}\mathrm{N}^{\circ} \\
\text { palabras }\end{array}$ \\
\hline 1 & averse & $\begin{array}{l}\text { es mayz cozido A } \\
\text { la noche y tostado } \\
\text { al dia con alguna } \\
\text { poca de carne / sy } \\
\text { averse podia (ls. } \\
3354-3355)\end{array}$ & $\begin{array}{l}\text { Chile - } \\
\text { Santiago, } \\
\text { Arauco, } \\
\text { literario, } 14- \\
12-1558 .\end{array}$ & Crónica & $\begin{array}{l}\text { verbo inf. } \\
+ \text { reflejo }\end{array}$ & $\begin{array}{l}\text { Reemplaza } \\
\text { a'tener' } \\
\text { como verbo } \\
\text { 'posesivo'. }\end{array}$ & 6 \\
\hline
\end{tabular}

Observaciones:

(1) En su forma moderna.

(2) Se desatan las abreviaturas pero se mantiene el resto de la escritura antigua.

(3) País y provincia analizados - documento $\mathrm{N}^{\mathrm{o}}$ - lugar de emisión del documento - tipo de documento - fecha de la emisión (día, mes, año).

(4) Tipología del documento.

(5) Sustantivo: indicar con el género: $m$ ó f. Verbo: tr. ó intr. ó r., etc.

(6) Valor semántico y/o sintáctico de la unidad.

(7) $\mathrm{N}^{\circ}$ de veces que aparece la palabra en el documento.

Como vemos, esta es una parte, la primera tal vez, de un conjunto mayor de desafíos que deben enfrentarse en el estudio histórico del español de Chile. La lingüística del corpus junto con los avances recientes en lingüística histórica del español proporcionan el marco de trabajo necesario para abordar con buenas perspectivas esta tarea. Nuestra tarea, así también es doble: constituir un corpus del español de Chile 
que sea lo suficientemente amplio para representar una tipología textual y estilística diversa, junto con conformar un panorama claro y coherente respecto del desarrollo de la sintaxis en el tiempo, de nuestra modalidad dialectal.

\section{OBRAS CITADAS}

Alvarez Nazario, Manuel. 1991. Historia de la lengua española en Puerto Rico. Su pasado y su presente en el marco de la realidad social, Academia Puertorriqueña de la Lengua Española, Santo Domingo.

Bosque, Ignacio y Violeta Demonte (eds.). 1999. Gramática descriptiva de la lengua española, 3 vols., Real Academia Española, Colección Nebrija y Bello; Espasa-Calpe, Madrid.

Cano Aguilar, Rafael (1995). "Problemas metodológicos en sintaxis histórica española", en Revista Española de Lingüística, 25, 2; Sociedad Española de Lingüística, Madrid; pp. 323-346.

Company Company, Concepción (dir.). 2006. Sintaxis histórica de la lengua española. Primera parte: la frase verbal, 2 vols., UNAM, Fondo de Cultura Económica, México.

Faarlund, Jan Terje. 1990. Syntactic change. Towards a theory of historical syntax, Mouton de Gruyter, Berlín.

Fontanella de Weinberg, $\mathrm{M}^{\mathrm{a}}$ Beatriz. 1997. El español bonaerense. Cuatro siglos de evolución lingüística (1580-1980), Hachette, Buenos Aires.

Frago, Juan Antonio y Mariano Franco Figueroa. 2001. El español de América, Universidad de Cádiz, Servicio de Publicaciones.

Hook, Hans Heinrich. 1991. Principle of historical linguistics, $2^{\text {nd }}$. ed. rev. \& up., Mouton de Gruyter, Berlín.

Kabatek, Johannes (ed.). 2008. Sintaxis histórica del español y cambio lingüístico: Nuevas perspectivas desde las tradiciones discursivas, Iberoamericana, Madrid.

Rojas, Elena M.. 1985. Evolución histórica del español en Tucumán entre los siglos XVI y XIX, Facultad de Filosofía y Letras, Universidad Nacional de Tucumán. 